\section{JURNAL EKONOMI EFEKTIF}

ISSN : $2622-8882$, E-ISSN : 2622-9935

Jurnal Ekonomi Efektif, Vol. 3, No. 1, Oktober 2020 @Prodi Manajemen Fakultas Ekonomi Universitas Pamulang

\title{
PENGARUH KUALITAS PELAYANAN TERHADAP KEPUASAN NASABAH PADA PT. BANK BRI CABANG BINTARO
}

\author{
Elizabeth Tika Kristina Hartuti ${ }^{1 *}$, Abdul Khoir ${ }^{2}$, Ade Yusuf ${ }^{3}$ \\ Universitas Pamulang \\ dosen01503@unpam.ac.id*
}

\begin{abstract}
ABSTRAK
Penelitian ini bertujuan untuk mengetahui pengaruh Kualitas Pelayanan terhadap Kepuasan Nasabah pada PT. Bank BRI Cabang Bintaro. Metode yang digunakan adalah explanatory research dengan sampel sebanyak 100 responden. Teknik analisis menggunakan analisis statistik dengan pengujian regresi, korelasi, determinasi dan uji hipotesis. Hasil penelitian ini variabel Kualitas Pelayanan diperoleh rata-rata skor sebesar 3,41 dengan kriteria baik. Variabel Kepuasan Nasabah diperoleh rata-rata skor sebesar 3,83 dengan kriteria baik. Kualitas Pelayanan berpengaruh signifikan terhadap Kepuasan Nasabah dengan persamaan regresi $\mathrm{Y}=8,849+0,865 \mathrm{X}$, dan nilai korelasi 0,787 atau kuat dengan determinasi $62,0 \%$. Uji hipotesis diperoleh signifikansi $0,000<0,05$.
\end{abstract}

\section{Kata Kunci: Kualitas Pelayanan, Kepuasan Nasabah.}

\begin{abstract}
This study aims to determine the effect of Service Quality on Customer Satisfaction at PT. Bank BRI Bintaro Branch. The method used is explanatory research with a sample of 100 respondents. The analysis technique uses statistical analysis with regression testing, correlation, determination and hypothesis testing. The results of this research variable Service Quality obtained an average score of 3.41 with good criteria. The Customer Satisfaction variable obtained an average score of 3.83 with good criteria. Service Quality has a significant effect on Customer Satisfaction with the regression equation $Y=8.849+0.865 X$, and a correlation value of 0.787 or strong with a determination of $62.0 \%$. Hypothesis testing obtained a significance of $0.000<0.05$.
\end{abstract}

Keywords: Service Quality, Customer Satisfaction. 


\section{PENDAHULUAN}

\section{A. Latar Belakang Masalah}

Dunia perbankan saat ini mengalami perkembangan yang sangat pesat, sehingga keadaan ini menimbulkan persaingan bisnis perbankan yang kompetitif dan ketat. Kenyataan seperti ini tidak dapat dipungkiri lagi sehingga setiap bank harus di tuntut untuk menggunakan berbagai cara dalam menarik minat nasabah.

Bank sebagai lembaga keuangan yang utamanya memberikan jasa penyimpanan dan menyalurkannya kembali dalam berbagai alternatif pinjaman kepada masyarakat juga perlu memfokuskan pada kinerja pelayanan untuk memuaskan nasabahnya.

Seiring dengan perkembangan yang dilakukan oleh pemerintah indonesia diera globalisasi ini kondisi sosial ekonomi masyarakat juga mengalami perubahan terutama nilai-nilai dan cara pandang yang dianut masyarakat. Semakin banyaknya perusahaan penyedia barang dan jasa akan menuntut masyarakat untuk lebih teliti dan kritis dalam memilih segala sesuatu yang dapat digunakan sebagai alat pemenuh kebutuhan. Perubahan kondisi masyarakat tersebut merupakan salah satu penyebab semakin ketatnya persaingan di berbagai bidang.

Dunia perbankan sangat penting bagi perekonomian indonesia, sehingga ada anggapan bahwa bank merupakan nyawa untuk menggerakkan roda perekonomian suatu negara, akan tetapi roda perbankan tidak dapat berjalan dengan baik apabila tidak didukung dengan adanya nasabah. Menurut Kasmir (2002:2) mengatakan bahwa "Bank adalah lembaga keuangan yang kegiatan usahanya adalah menghimpun dana dari masyarakat dan menyalurkan kembali dana tersebut ke masyarakat serta memberikan jasa-jasa bank lainnya". Lembaga keuangan seperti perbankan merupakan instrumen yang sangat penting dalam memperlancar pembangunan suatu bangsa, Menurut Roine dan Tatik Suryani (2001:273) mengatakan bahwa "Kualitas pelayanan menjadi komponen utama karena produk-produk utama bank yaitu kredit yang merupakan suatu penawaran yang tidak berbeda dan pelayanan bank mudah ditiru, oleh karena itu persaingan akan sangat dipengaruhi oleh kemampuan memberikan pelayanan terbaik dan bermutu dibandingkan oleh bank pesaing". Salah satu fungsi bank adalah menghimpun dana dari masyarakat. Bank di tuntut untuk lebih inovatif dan profesional dalam menghasilkan produk-produknya agar menarik minat masyarakat agar menyimpan dananya di bank. Dengan bertambahnya dana yang masuk maka bank akan lebih leluasa menyalurkan dananya kepada pihak-pihak yang menyalurkan dalam pembiayaan usahanya. Dengan demikian, bank akan mendapatkan keuntungan (spread) yaitu selisih bunga pinjaman dengan bunga simpanan dan juga membantu memperlancar pembangunan ekonomi.

Dengan semakin majunya revolusi teknologi komunikasi dan informasi mengakibatkan terjadinya perubahan (change) yang luar biasa. Adanya kemudahan yang diperoleh dari teknologi informasi dan komunikasi mengakibatkan munculnya kompetisi yang sangat ketat sehingga nasabah (customer) semakin banyak pilihan dan semakin sulit untuk dipuaskan karena telah terjadi pergeseran yang semula hanya untuk memenuhi kebutuhan meningkat menjadi harapan (expectation) untuk memenuhi kepuasan. Sehingga bagi perusahaan, kunci kearah profitabilitas bukan lagi volume penjualan melainkan kepuasan jangka panjang dan menjadikan nasabah yang setia dan loyal.

Penilaian akan kualitas layanan yang di kenal dengan service quality (servqual), yang berdasarkan atas lima dimensi kualitas yaitu tangibles (bukti langsung), reliability (kehandalan), responsivennes (daya anggap), assurance (jaminan) dan emphaty (empati) (Kotler. 2009:53).

Teori singkat variabel X ( Kualitas Pelayanan ) kualitas pelayanan merupakan 
suatu bentuk penilaian konsumen terhadap tingkat pelayanan yang di terima (percieved service) dengan tingkat layanan yang di harapkan (expected service) ( Fandy Tjiptono. 2008:18).

Teori singkat variabel Y ( Kepuasan Nasabah ) dalam bidang jasa merupakan elemen penting dan menentukan dalam menumbuh kembangkan perusahaan agar tetap eksis dalam menghadapi persaingan. Kepuasan (satisfaction) adalah perasaan senang atau kecewa seseorang yang timbul karena membandingkan kinerja yang di persepsikan produk (hasil) terhadap harapan (ekspektasi) mereka, Jika kinerja gagal memenuhi harapan pelanggan maka pelanggan akan tidak puas, Jika kinerja melebihi harapan maka pelanggan akan sangat puas atau senang"(Kotler. 2009:139).

Bisnis perbankan merupakan bisnis yang berdasar pada azas kepercayaan, Masalah kualitas pelayanan (service quality) menjadi faktor penting dalam menentukan keberhasilan bisnis perbankan. Hal ini juga terjadi pada PT. Bank BRI Cabang Bintaro Tangerang Selatan. Sebagai tempat penelitian ini, Kualitas pelayanan merupakan hal penting yang perlu di perhatikan.

Hubungan dari kedua teori variabel X dan Y (Kualitas dan Kepuasan) kualitas dan kepuasan adalah satu bagian yang tidak dapat terpisahkan dengan pelayanan, kualitas memberikan dorongan kepada pelanggan untuk menjalin ikatan yang kuat dengan perusahaan. Ikatan seperti ini dalam jangka panjang memungkinkan perusahaan untuk memahami dengan seksama harapan serta kebutuhan nasabah, dengan demikian perusahaan tersebut dapat meningkatkan kepuasan nasabah dimana perusahaan memaksimumkan pengalaman nasabah yang menyenangkan dan meminimumkan atau meniadakan pengalaman nasabah yang kurang menyenangkan.

Pentingnya kepuasan nasabah pada PT. Bank BRI Cabang Bintaro Tangerang Selatan adalah baik atau buruknya pelayanan yang diberikan kepada nasabah akan berakibat timbulnya permasalahan yang lebih kompleks. Apabila nasabah tidak merasa puas atas pelayanan maka pelanggan tersebut akan menyampaikan pengalaman buruknya kepada orang lain dan dapat merugikan citra perusahaan.

Untuk meningkatkan kualitas pelayanan PT. Bank BRI Cabang Bintaro Tangerang Selatan bekerjasama dengan perusahaan yang ada di daerah Gading Serpong dengan bentuk kerjasama pembayaran gaji karyawan secara on line yang di sebut payroll dengan cara membuka rekening PT. Bank BRI Cabang Bintaro Tangerang Selatan selain itu PT. Bank BRI Cabang Bintaro Tangerang Selatan. Gading Serpong membuka beberapa unit ATM di beberapa tempat strategis yaitu di Gading Serpong dan beberapa ATM bersama serta beberapa tempat strategis lainnya agar nasabah PT. Bank Index Selindo dapat dengan mudah menggunakan jasa penarikan uang tunai secara cepat tanpa harus mengantri.

Upaya peningkatan kualitas pelayanan oleh PT. Bank BRI Cabang Bintaro bersifat inovatif dan berorientasi kepada kepuasan nasabah, namun masih ada pertanyaan, apakah hal tersebut telah memberikan kepuasan bagi nasabah PT. Bank BRI Cabang Bintaro, bila dilihat dari lima dimensi pelayanan yaitu tangibles (bukti langsung), reability (kehandalan, responsiveness (daya tanggap), assurance (jaminan) dan emphaty (empati). PT. Bank BRI Cabang Bintaro perlu mengidentifikasi apakah pelayanan yang selama ini di berikan telah sesuai dnegan harapan nasabah, hal ini merupakan bukti perhatiannya terhadap kepuasan nasabah. Apabila harapan nasabah lebih besar dari tingkat layanan yang di terima maka nasabah tidak puas, sebaliknya apabila harapan nasabah sama atau lebih kecil dari tingkat pelayanan yang di terima, maka nasabah akan puas. Dari hasil pra-riset yang penulis lakukan telah di temukan beberapa gejala masalah, diantaranya : Pelayanan kurang optimal, Nasabah prioritas kurang mendapat pelayanan prima, 
Nasabah baru kurang puas dengan pelayanan kesigapan dalam menanggapi komplain, Nasabah baru merasa kurang puas terhadap keramahan yang diberikan.

Berdasarkan gejala masalah di atas maka penulis tertarik mengadakan penelitian dengan judul "Pengaruh kualitas pelayanan terhadap tingkat kepuasan nasabah pada PT. Bank BRI Cabang Bintaro"

\section{B. Rumusan Masalah}

1. Bagaimana Kualitas Pelayanan pada pada PT. Bank BRI Cabang Bintaro ?.

2. Bagaimana Kepuasan Nasabah pada PT. Bank BRI Cabang Bintaro ?.

3. Adakah pengaruh antara Kualitas Pelayanan terhadap Kepuasan Nasabah pada PT. Bank BRI Cabang Bintaro ?.

\section{Tujuan Penelitian}

1. Untuk mengetahui kondisi Kualitas Pelayanan pada PT. Bank BRI Cabang Bintaro ?.

2. Untuk mengetahui kondisi Kepuasan Nasabah pada PT. Bank BRI Cabang Bintaro ?.

3. Untuk mengetahui pengaruh antara Kualitas Pelayanan terhadap Kepuasan Nasabah pada PT. Bank BRI Cabang Bintaro ?.

\section{METODE PENELITIAN}

\section{Populasi}

Populasi dalam penelitian ini berjumlah 100 responden PT. Bank BRI Cabang Bintaro

\section{Sampel}

Teknik pengambilan sampling dalam penelitian ini adalah samplel jenuh, dimana semua anggota populasi dijasikan sebagai sampel. Dengan demikian sampel dalam penelitian ini berjumlah 100 responden.

\section{Jenis Penelitian}

Jenis penelitian yang dipakai adalah asosiatif, dimana tujuannya adalah untuk mengetahui mencari keterhubungan antara variabel independen terhadap variabel dependennya

\section{Metode Analisis Data}

Dalam menganalisis data digunakan uji validitas, uji reliabilitas, analisis regresi linier sederhana, koefisien korelasi, koefisien determinasi dan uji hipotesis.

\section{HASIL PENELITIAN DAN PEMBAHASAN}

\section{Analisis Deskriptif}

Pada pengujian ini digunakan untuk mengetahui skor minimum dan maksimum skor tertinggi, ratting score dan standar deviasi dari masing-masing variabel. Adapun hasilnya sebagai berikut:

Tabel 1. Hasil Analisis Descriptive Statistics

\section{Descriptive Statistics}

\begin{tabular}{|l|l|r|r|r|r} 
& N & Minimum & Maximum & Mean & \multicolumn{1}{c}{ Std. Deviation } \\
\hline Kualitas Pelayanan (X) & 100 & 28 & 44 & 34.14 & 3.843 \\
\hline Kepuasan Nasabah (Y) & 100 & 29 & 49 & 38.38 & 4.223 \\
\hline Valid N (listwise) & 100 & & & & \\
\hline
\end{tabular}

Kualitas Pelayanan diperoleh varians minimum sebesar 28 dan varians maximum 44 dengan ratting score sebesar 3,41 dengan standar deviasi 3,843.

Kepuasan Nasabah diperoleh varians minimum sebesar 29 dan varians maximum 49 dengan ratting score sebesar 3,83 dengan standar deviasi 4,223. 


\section{Analisis Verifikatif.}

Pada analisis ini dimaksudkan untuk mengetahui pengaruh variabel independen terhadap variabel dependen. Adapun hasil pengujian sebagai berikut:

\section{a. Analisis Regresi Linier Sederhana}

Uji regresi ini dimaksudkan untuk mengetahui perubahan variabel dependen jika variabel independen mengalami perubahan. Adapun hasil pengujiannya sebagai berikut:

Tabel 2. Hasil Pengujian Regresi Linier Sederhana Coefficients $^{a}$

\begin{tabular}{l|l} 
Unstandardized Standardized &
\end{tabular}

Coefficients Coefficients

\begin{tabular}{l|r|r|r|r|r} 
Model & \multicolumn{1}{c}{ B } & Std. Error & Beta & \multicolumn{1}{c}{ t } & \multicolumn{1}{c}{ Sig. } \\
\hline 1 (Constant) & 8.849 & 2.352 & & 3.762 & .000 \\
\hline Kualitas Pelayanan $(X)$ & .865 & .068 & .787 & 12.635 & .000 \\
\hline
\end{tabular}

a. Dependent Variable: Kepuasan Nasabah (Y)

Berdasarkan hasil pengujian pada tabel di atas, diperoleh persamaan regresi $\mathrm{Y}$ $=8,849+0,865 X$. Dari persamaan tersebut dijelaskan sebagai berikut:

1) Konstanta sebesar 8,849 diartikan jika Kualitas Pelayanan dan motivasi tidak ada, maka telah terdapat nilai Kepuasan Nasabah sebesar 8,849 point.

2) Koefisien regresi Kualitas Pelayanan sebesar 0,865, angka ini positif artinya setiap ada peningkatan Kualitas Pelayanan sebesar 0,865 maka Kepuasan Nasabah juga akan mengalami peningkatan sebesar 0,865 point.

\section{b. Analisis Koefisien Korelasi}

Analisis koefisien korelasi dimaksudkan untuk mengetahui tingkt kekuatan hubungan dari variabel independen terhadap variabel dependen baik secara parsial maupun simultan. Adapun hasil pengujian sebagai berikut:

Tabel 3. Hasil Pengujian Koefisien Korelasi Kualitas Pelayanan Terhadap Kepuasan Nasabah.

\begin{tabular}{llrr} 
& \multicolumn{1}{c}{ Correlations $^{\mathbf{b}}$} & \multicolumn{1}{c}{$\begin{array}{c}\text { Kualitas } \\
\text { Pelayanan (X1) }\end{array}$} & \multicolumn{1}{c}{$\begin{array}{c}\text { Kepuasan } \\
\text { Nasabah (Y) }\end{array}$} \\
\hline Kualitas Pelayanan (X) & Pearson Correlation & 1 & $.787^{\star *}$ \\
\cline { 2 - 4 } & Sig. (2-tailed) & .000 \\
\hline Kepuasan Nasabah (Y) & Pearson Correlation & $.787^{* *}$ & 1 \\
\cline { 2 - 4 } & Sig. (2-tailed) & .000 & \\
\hline
\end{tabular}

${ }^{* *}$. Correlation is significant at the 0.01 level (2-tailed).

b. Listwise $\mathrm{N}=100$

Berdasarkan hasil pengujian diperoleh nilai korelasi sebesar 0,787 artinya Kualitas Pelayanan memiliki hubungan yang kuat terhadap Kepuasan Nasabah.

\section{c. Analisis Koefisien Determinasi}

Analisis koefisien determinasi dimaksudkan untuk mengetahui besarnya persentase pengaruh dari variabel independen terhadap variabel dependen. Adapun hasil pengujian sebagai berikut:

Tabel 4. Hasil Pengujian Koefisien Determinasi Kualitas Pelayanan Terhadap

Kepuasan Nasabah.

Model Summary

\begin{tabular}{l|r|rr|r} 
& & & Adjusted R & \multicolumn{2}{c}{$\begin{array}{c}\text { Std. Error of the } \\
\text { Model }\end{array}$} & R & R Square & Square & Estimate \\
\hline 1 & $.787^{a}$ & .620 & .616 & 2.618 \\
\hline a. Predictors: (Constant), Kualitas Pelayanan (X1)
\end{tabular}

Berdasarkan hasil pengujian diperoleh nilai determinasi sebesar 0,620 artinya 
Kualitas Pelayanan memiliki kontribusi pengaruh sebesar 62,0\% terhadap Kepuasan Nasabah.

\section{d. Uji Hipotesis}

Pengujian hipotesis dengan uji t digunakan untuk mengetahui hipotesis mana yang diterima.

Rumusan hipotesis: Terdapat pengaruh yang signifikan antara Kualitas Pelayanan terhadap Kepuasan Nasabah.

Tabel 5. Hasil Uji Hipotesis Kualitas Pelayanan Terhadap Kepuasan Nasabah.

\section{Coefficients $^{a}$}

Unstandardized Standardized

\begin{tabular}{l|r|r|r|r|r}
\multicolumn{5}{c}{} & \multicolumn{2}{c}{ Coefficients } & \multicolumn{2}{c|}{$\begin{array}{c}\text { Coefficients } \\
\text { Model }\end{array}$} & \multicolumn{1}{c}{ B } & Std. Error & Beta & \multicolumn{1}{c|}{$\mathrm{t}$} & \multicolumn{1}{c}{ Sig. } \\
\hline 1 & 8.849 & 2.352 & & 3.762 & .000 \\
\hline Kualitas Pelayanan $(\mathrm{X})$ & .865 & .068 & .787 & 12.635 & .000 \\
\hline
\end{tabular}

a. Dependent Variable: Kepuasan Nasabah $(\mathrm{Y})$

Berdasarkan hasil pengujian pada tabel di atas, diperoleh nilai t hitung $>\mathrm{t}$ tabel atau $(12,635>1,989)$, dengan demikian hipotesis yang diajukan bahwa terdapat pengaruh yang signifikan atara Kualitas Pelayanan terhadap Kepuasan Nasabah diterima.

\section{PEMBAHASAN HASIL PENELITIAN}

\section{Kondisi Jawaban Responden Variabel Kualitas Pelayanan}

Berdasarkan jawaban responden, variabel Kualitas Pelayanan diperoleh ratting score sebesar 3,41 berada di rentang skala 3,40 - 4,19 dengan kriteria baik atau setuju.

\section{Kondisi Jawaban Responden Variabel Kepuasan Nasabah}

Berdasarkan jawaban responden, variabel Kepuasan Nasabah diperoleh ratting score sebesar 3,83 berada di rentang skala 3,40 - 4,19 dengan kriteria baik atau setuju.

\section{Pengaruh Kualitas Pelayanan Terhadap Kepuasan Nasabah}

Kualitas Pelayanan berpengaruh signifikan terhadap Kepuasan Nasabah dengan persamaan regresi $\mathrm{Y}=17,517+0,565 \mathrm{X}$, nilai korelasi sebesar 0,787 atau memiliki hubungan yang kuat dengan kontribusi pengaruh sebesar 62,0\%. Pengujian hipotesis diperoleh nilai t hitung $>\mathrm{t}$ tabel atau $(12,635>1,989)$. Dengan demikian hipotesis yang diajukan bahwa terdapat berpengaruh signifikan antara Kualitas Pelayanan terhadap Kepuasan Nasabah diterima.

\section{PENUTUP}

\section{Kesimpulan}

a. Variabel Kualitas Pelayanan diperoleh ratting score sebesar 3,41 berada di rentang skala 3,40 - 4,19 dengan kriteria baik atau setuju.

b. Variabel Kepuasan Nasabah diperoleh ratting score sebesar 3,83 berada di rentang skala 3,40 - 4,19 dengan kriteria baik atau setuju.

c. Kualitas Pelayanan berpengaruh signifikan terhadap Kepuasan Nasabah dengan persamaan regresi $\mathrm{Y}=17,517+0,565 \mathrm{X}$, nilai korelasi sebesar 0,787 atau kuat dan kontribusi pengaruh sebesar $62,0 \%$ sedangkan sisanya sebesar $57,9 \%$ dipengaruhi faktor lain. Uji hipotesis diperoleh nilai $t$ hitung $>t$ tabel atau $(12,635>1,989)$. 


\section{Saran}

a. Kualitas pelayanan PT. Bank BRI Cabang Bintaro harus ditingkatkan lagi sehingga mencapai interpretasi sangat kuat pengaruhnya terhadap kepuasan, dengan demikian dapat menjaring nasabah yang lebih banyak lagi.

b. Dewasa ini iklan melalui media elektronik terbukti cukup efektif dalam upaya menjaring nasabah, oleh sebab itu Perusahaan harus memikirkan strategi ini agar lebih dikenal masyarakat luas.

\section{DAFTAR PUSTAKA}

Algifari. (2015). "Analisis Regresi untuk Bisnis dan Ekonomi”. Yogyakarta: BPFE.

Arikunto, Suharsimi (2014). "Prosedur Penelitian Suatu Pendekatan Praktek". Jakarta: Rineka Cipta.

Bashu Swastha dan T. Handoko (2015) Manajemen Pemasaran Moderen, Yogyakarta: BPFE.

Basu Swastha Dharmmesta. (2014). Manajemen Pemasaran. BPFE: Yogyakarta. Buchari Alma. 2014. Manajemen pemasaran dan Pemasaran Jasa. Edisi Revisi.

Bilson Simamora (2016) Panduan Riset Prilaku Konsumen, Jakarta: PT. Gramedia Pustaka.

Fandy Tjiptono (2017), Serivce Quality and Satisfiation. Jakarta: Edisi tiga. Andi.

Freddy Rangkuti (2016) Strategi Promosi Yang Kreatif, Edisi Pertama, Cetakan Pertama Jakarta: Gramedia Pustaka Utama.

Imam Ghozali (2017). "Aplikasi Analisis Multivariate Dengan Program SPSS”. Edisi Kelima. Semarang: Badan Penerbit Undip.

Istijanto (2014) "Riset Sumber Daya Manusia”. Jakarta: PT. Gramedia Pustaka

Kharis, Ismu Fadli (2011). "Studi Mengenai Impulse Buying dalam Penjualan Online”. Semarang : Skripsi Universitas Diponegoro

Kotler dan Amstrong (2017), Prinsip-prinsip Pemasaran. Edisi Kedua Belas”. Jilid Satu. Jakarta: Erlangga.

Lupiyoadi (2016) Manajemen Pemasaran Jasa, Edisi 4, Jakarta: Salemba Empat.

Philip Kotler (2017) Manajemen Pemasaran, Edisi Keempat Belas, Jakarta: PT. Indeks.

Phipil Kotler dan Kevin Keller (2017) Manajemen Pemasaran, Edisi Kedua Belas, Jilid Satu, Jakarta: Erlangga.

Rao, Purba, (2012). "Measuring Consumer Perceptions Through Factor Analysis", The Asian.

Santoso, Singgih (2015). "Menguasai Statistik Multivariat”. Jakarta: PT Elex Media Komputindo.

Sudjana (2014) “Metode Statistika”, Bandung: Tarsido.

Sugiyono (2017), "Metode Penelitian Administrasi : dilengkapi dengan Metode $R \&$ D”. Bandung: Alfabeta.

Suhartanto (2014). "Metode Riset Pemasaran”. Bandung: Alfabeta

Sunarsi, D. (2017). Pengaruh Rekrutmen, Seleksi dan Pelatihan Terhadap Produktivitas Kerja Karyawan PT Mercolade Tangerang.

Sunarsi, D. (2018). Pengembangan Sumber Daya Manusia Strategik \& Karakterisrik Sistem Pendukungnya: Sebuah Tinjauan. Jurnal Ilmiah MEA (Manajemen, Ekonomi, \& Akuntansi). Vol 2 No 3

Yuangga, K. D., \& Sunarsi, D. (2018). The Influence of Procrastination and Low Time Management on Student Self Efficacy (at MA Soebono Mantofani). PINISI Discretion Review, 2(1), 85-92. 